\title{
TO EXEMPT OR NOT TO EXEMPT ${ }^{1}$ - SOME LESSONS FOR EDUCATORS AND ADMINISTRATORS
}

\author{
Karthy Govender \\ LLB LLB LLM \\ Professor of Law \\ University of KwaZulu-Natal, \\ Howard College Campus, Durban \\ Commissioner on the South African \\ Human Rights Commission \\ Rowena Bernard \\ LLB LLM \\ Lecturer, Law Faculty \\ University of KwaZulu-Natal \\ Howard College Campus, Durban
}

\section{SUMMARY}

Schools are required to reasonably accommodate the cultural and religious rights of their learners. They can depart from these responsibilities if to do so would impose an undue burden on their core activity which is to provide effective education. These norms require the schools to exercise what can be described as a judicial discretion. This article, by drawing on the judgment of MEC for Education: Kwazulu-Natal v Naveneethum Pillay, seeks to assist schools in the discharge of these responsibilities and ensure that the decisions made by the educators are consistent with the Constitution of South Africa Act 108 of 1996. The law now imposes a wide and demanding discretion upon educators and we suggest guidelines that we hope will assist and structure the exercise of this discretion. We also suggest a draft set of rules which incorporates an exemption process which school governing bodies can adopt to proactively bring their Codes of Conduct in line with the demands of the law.

MEC for Education: Kwazulu-Natal v Naveneethum Pillay 20082 BCLR 99 (CC). This article is a MARIP B initiative of the Law Faculty of the University of KwaZulu-Natal. 


\section{INTRODUCTION}

Despite profound policy and legislative changes aimed at desegregating education in SA, patterns of segregation stubbornly persist in various sectors of our education system.

Durban Girls' High School (DGHS), a former model C school which previously served the white community exclusively, has successfully managed to change the demographics of the school whilst still producing excellent academic results. It was described as an educationally excellent school which is at the cutting edge of non-racial education. Despite this, it was found by a majority of justices in MEC for Education: Kwazulu-Natal v Naveneethum Pillay (the Pillay case) to have unfairly discriminated against Ms Sunali Pillay on the basis of her culture by threatening to discipline her for wearing a nose stud whilst at school. This dispute and the consequent litigation which were protracted and distracting, illustrate the serious challenges confronting SA schools as they seek to align their codes of conduct and practices with the requirements of the Constitution of the Republic of SA, 1996 (hereinafter "the Constitution") and applicable legislation.

The constitutional challenges brought against the decision of DGHS illustrate that schools have to do more than just act in good faith and discharge their core obligation of providing effective and relevant education. The proposition that schools are required to act in accordance with the law and the Constitution when discharging their core functions now has to be taken seriously. The purpose of this paper is to describe and analyze the Pillay case and suggest recommendations to governing bodies as to how to bring their codes of conduct proactively in line with the requirements of the Constitution.

The relevant parts of the DGHS code did not appear to permit exemptions to its policy pertaining to uniforms. ${ }^{2}$ However, it was accepted that exemptions were in fact granted primarily to accommodate the wearing of religious symbols. A practice had developed of allowing Hindu girls to wear Luxmi strings ${ }^{3}$ in honour of Luxmi, goddess of prosperity and light, and of allowing African girls to wear hide bracelets as a mark of respect for deceased relatives. Thus, despite there being no provision for exemptions in the Code, a practice had developed which accommodated the manifestation of certain religious beliefs. Despite this, Sunali chose not to apply for an exemption, but rather, in direct violation of the Code, to arrive at school after a school holiday with her nose pierced with a stud. ${ }^{4}$

2 Pillay case par 5 refers to the uniform policy of the DGHS and reads as follows:

"Jewellery: Ear-rings - plain round studs/sleepers may be worn, ONE in each ear lobe at the same level. No other jewellery may be worn, except a wristwatch. Jewellery includes any adornment/bristle which may be in any body piercing. Watches must be in keeping with the school uniform. Medic-Alert discs may be worn."

3 A Luxmi string is a red string worn around the wrist of Hindu people.

$4 \quad$ Pillay case par 5. 
It is our submission that the learner's failure to apply for an exemption should have been sufficient cause for the Constitutional Court to dismiss this application. In City Council of Pretoria v Walker, ${ }^{5}$ the court cautioned against applicants resorting to self-help in order to enforce constitutional rights. In a constitutional democracy disputes about law, fact or a mixture of both must ultimately be resolved or settled by a court or an independent arbiter. One of the parties to the dispute cannot unilaterally determine the outcome and then decide on the remedy he or she deems to be most appropriate. Thus, in this instance, an application for an exemption ought to have been made and if that was unsuccessful, the internal appeal procedure exhausted and finally an application should have been made to the courts. A learner cannot, in the belief that the rule may be unconstitutional, act in defiance of school rules and processes.

The court indicated that the manner in which Ms Pillay, Sunali's mother, dealt with the issue left much to be desired. ${ }^{6}$ However, it held that this had minimal relevance to the question of fairness. In a climate where schools and educational institutions are struggling to assert their authority effectively, the court ought to have placed greater weight on the failure of the applicants to request an exemption. Rules that have been promulgated after a participatory process must be respected until changed. Every effort must be made to support principals and educators to maintain discipline within the framework of the Constitution.

However, it is now clear that if learners choose to ignore existing procedures permitting applications for exemptions, the courts are unlikely to take as benevolent an approach as they adopted with Sunali. They will, in all probability, find that the failure to apply for an exemption is fatal to any application to enforce rights against a school. Perceived defiance of rules will not implicitly or explicitly be condoned.

\section{THE RIGHT TO EQUALITY}

It is trite that all the legislation regulating the functioning of schools and the formulation of education policy is subject to the Constitution. A number of laws such as section 7 of the SA Schools $\mathrm{Act}^{7}$ impose an obligation on schools to discharge their duties in a manner that is consistent with the Constitution.

We have come to realize, on a more mature interpretation of the Constitution, ${ }^{8}$ that little purpose is served by creating a hierarchy of rights or by asserting, in absolute terms, that a particular right is more important than other rights in all contexts. The importance of a right will depend on the

\footnotetext{
19982 SA 363 (CC).

Pillay case par 108 .

S 7 of the South African Schools Act 84 of 1996 provides:

"Subject to the Constitution and any applicable provincial law, religious observances may be conducted at a public school under rules issued by the governing body if such observances are conducted on an equitable basis and attendance at them by learners and members of staff is free and voluntary."

8 The Constitution of the Republic of South Africa, 1996.
} 
context in which it is asserted or claimed. Notwithstanding this, the right to equality is of fundamental importance to the restructuring of the South African society. This is unsurprising as the liberation struggle and the resistance to apartheid were premised on the fight for equality. In addition, South Africa remains one of the most unequal societies in the world.

The achievement of equality is one of the founding values of the Constitution. ${ }^{9}$ It is also not coincidental that the right to equality is the first substantive right that is protected in the Bill of Rights. The right has been interpreted extensively and a coherent, comprehensive and sound jurisprudence has developed around the right. For present purposes it would suffice to state that section 9(3) of the Constitution prohibits unfair discrimination directly or indirectly on 17 grounds including religion, culture or ethnic origin. By prohibiting both direct and indirect discrimination, the Constitution seeks to end the discriminatory practices. The issue is not whether the person, who is alleged to have unfairly discriminated, intends to do so but rather whether the conduct, from an objective perspective, has the effect of unfairly discriminating. The issue in Pillay was whether Sunali was unfairly discriminated against on the basis of culture. It is also important to point out that the list of specified grounds is not exhaustive.

Section 9(4) of the Constitution requires that national legislation be enacted to prevent or prohibit unfair discrimination by any person. Parliament has enacted the Promotion of Equality and the Prevent of Unfair Discrimination Act 4 of 2000 (Equality Act) to ensure that the prohibition against unfair discrimination is now applicable against the State and all persons. The Act prohibits the State or any person from unfairly discriminating against another person on any of the prohibited grounds. ${ }^{10}$ The Act thus regulates the relationship between the State and individuals and between individuals themselves in so far as unfair discrimination is concerned. Special Equality Courts, staffed by trained magistrates and judges, have been set up in various centres throughout the country. These courts are meant to function expeditiously, process cases informally and facilitate participation by the parties to the proceedings. ${ }^{11}$ The Equality Courts have wide powers which include: the powers to make declaratory orders (stating the rights of the parties), order the payment of damages in respect of proven financial loss or psychological suffering, order audits to be conducted, order that an unconditional apology be made and order that practices and policies be changed. ${ }^{12}$

In order to avoid some of the problems that have plagued other jurisdictions interpreting equality laws, the Equality Act gives the applicant considerable assistance by reversing the onus of proof in some circumstances. In terms of the Act, ${ }^{13}$ once the applicant adduces evidence of discrimination on one of the prohibited grounds, the onus shifts to the

\footnotetext{
$\mathrm{S} 1$ of the Constitution.

S 6 of the Equality Act.

$\mathrm{S} 4$ of the Equality Act.

$\mathrm{S} 21$ of the Equality Act.

$\mathrm{S} 13$ of the Equality Act.
} 
respondent to prove that the discrimination was not unfair. Discrimination is different from differentiation. Discrimination is differentiation which adversely impacts on or undermines human dignity. Discrimination refers to instances where a person is denied a benefit or has a burden imposed on him or her on a ground that adversely affects his or her human dignity. The applicant must provide credible evidence that the denial of the benefit or the burden imposed on him or her was based on one of the prohibited grounds. If the applicant discharges this burden then the respondent is required to justify the decision by proving that the discrimination was fair.

The DGHS responded to Sunali Pillay's wearing of the nose stud at school by issuing an instruction that she had to remove it after a month. ${ }^{14}$ This indulgence was granted in order to allow the piercing to heal so that the nose stud would be able to be inserted and removed on a daily basis. ${ }^{15}$ However, after the expiry of the month, Sunali continued to wear the nose stud. ${ }^{16}$ Ms Pillay wrote a letter to the school indicating that the insertion of the nose stud was part of a time-honoured family tradition and that it was meant to indicate that the child was eligible for marriage. ${ }^{17}$ This practice, according to Ms Pillay, is a method of honouring daughters as responsible adults. ${ }^{18}$ The school was unpersuaded and directed Sunali to remove the nose stud or face disciplinary proceedings. ${ }^{19}$ Ms Pillay sought to pre-empt disciplinary proceedings by seeking an interdict in the Equality Court. ${ }^{20} \mathrm{Her}$ contention was that the refusal of the school to allow her daughter to wear the nose stud amounted to unfair discrimination as this was a practice that was followed by the South Indian community for centuries. ${ }^{21}$

Ms Pillay was unsuccessful in the Equality Court but succeeded in an appeal to the High Court. The High Court held that as the nose stud had religious and or cultural significance to Sunali, the failure to treat her differently from her peers amounted to withholding from her the benefit, opportunity and advantage of enjoying fully her culture and of practising her religion. ${ }^{22}$ The court accordingly found that the conduct of the school amounted to unfair discrimination. ${ }^{23}$ The school and the Department of Education appealed the decision to the Constitutional Court.

The court specifically identified both the decision not to grant Sunali an exemption and the code of the school itself as being problematic. ${ }^{24}$ The Code of DGHS was problematic in that it did not set out a process or standard according to which exemptions could be applied for and granted. ${ }^{25}$

\footnotetext{
Pillay case par 6 .

Pillay case par 7.

Pillay case par 6.

Pillay case par 7.

Pillay case par 8.

Pillay case par 14

Pillay case par 10

Pillay case par 11.

Pillay case par 15

Pillay case par17.

Pillay case par 36

Pillay case par 37.
} 
Secondly the jewellery prohibition in the code required Sunali to seek an exemption. ${ }^{26}$ The court was emphatic that a properly drafted code which permitted exemptions would avoid acrimonious disputes and assist DGHS in exercising its discretion. ${ }^{27}$ One of the important lessons of this judgment is that all schools must incorporate into their code of conduct, processes for the granting of exemptions in appropriate circumstances.

\section{WAS THERE DISCRIMINATION EVEN THOUGH THE CODE APPLIED UNIFORMLY TO ALL LEARNERS?}

The concept of discrimination suggests disparity of treatment between persons to the prejudice of someone. Thus, for Sunali to establish discrimination, she would have to demonstrate that some other group/person was being treated more favourably. The school argued that there was no comparator and that the prohibition applied to everyone equally and that therefore there was no discrimination. ${ }^{28}$ The court held that there was a comparator in this case. The comparison was between those learners whose sincerely held religious and cultural beliefs were compromised by the code and those whose beliefs were not compromised by the code. ${ }^{29}$ This is extremely wide and would in effect render redundant the need to establish a comparator. The separate judgment of O'Regan $\mathrm{J}$ narrows this considerably by finding a comparator between those learners who have been afforded an exemption to pursue their cultural and religious practices as against those who have been denied an exemption. ${ }^{30}$

On the majority view, there would be no need to show that different treatment was afforded to various learners. If the overall consequence of the code is the unequal treatment of learners, then the most appropriate section to deal with this would be section 9(1) which provides that everyone is equal before the law and has the right to equal protection and benefit of the law. The approach of the majority appears to conflate both the 9(1) and 9(3) enquiries by effectively finding a comparator in the potentially unequal treatment by the law. On Justice O' Regan's approach it is necessary to point to differential treatment and this appears to be more consistent with the existing jurisprudence that has developed around section 9(1) and 9(3) of the Constitution. Section 9(1) deals with unequal treatment before the law and section 9(3) ensures that people are not unfairly discriminated against when compared with other people. In this case exemptions were granted and thus there was no need for the court to adopt as wide an approach as the majority did.

Pillay case par 37.

Pillay case par 38.

Pillay case par 42.

Pillay case par 44.

Pillay case par164. 


\section{THE GENUINENESS OF THE BELIEF AND ESTABLISHING DISCRIMINATION}

The genuineness of a religious practice can be objectively verified relatively easily. Given the compulsory and binding nature of these practices, it was understandable for schools to draw a distinction between compulsory and binding religious practices on the one hand and non-binding voluntary cultural practices on the other. A greater degree of accommodation was afforded to the former than to the latter. The court specifically eschews any distinction between culture and religion. Clearly, recognized cultural beliefs can be assessed and evaluated. It will, however, be much more difficult if the learner asserts a cultural belief that is contested within the culture itself. It would be invidious for the school to try and ascertain the outer limits of any particular culture.

The English Courts have offered a definition of what constitutes an "ethnic group". ${ }^{31}$ The group must have a long-shared history and cultural tradition of their own. ${ }^{32}$ Other relevant factors would include common geographical origin, a common language, a common literature peculiar to the group and a common religion different from that of neighbouring groups. ${ }^{33}$ Thus, it is a combination of religion, language, geographical origin, ethnicity and artistic traditions which determines the culture of a person. The court in Pillay was of the view that this definition was too restrictive and ought to be wider. ${ }^{34}$ It refrained from elaborating upon the definition as Sunali was clearly part of the South Indian Tamil cultural group which in any event fell within the narrow definition of culture. ${ }^{35}$ A cultural practice is enjoyed in association with others and therefore the factors suggested by the English Courts provide a useful starting point to determine whether the exemption requested in a legitimate cultural practice. The greater the number of people that engage in the practice, the more likely it is to be a genuinely held cultural belief. The more contested the belief, the more justified the school would be to require clearer proof of the genuineness of the belief.

According to the court an individual's cultural convictions may be as fundamental to their beings as their religious convictions. ${ }^{36}$ Thus the decision to deny the expression of a cultural belief may be as egregious as denying a person the right to manifest their religious beliefs. The court emphasized that differentiating between mandatory and voluntary practices does not affirm diversity but simply tolerates or permits it. ${ }^{37}$ Thus the court concluded that the voluntariness or otherwise of a cultural practice is irrelevant to the determination of whether it qualifies for protection. ${ }^{38}$ Both compulsory and

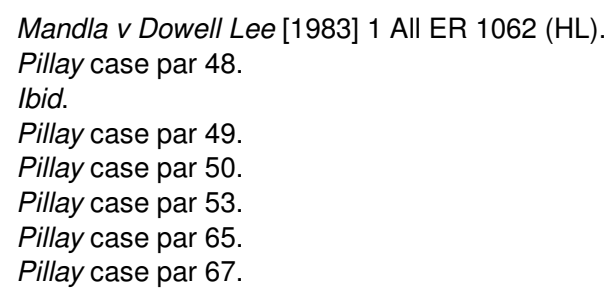


voluntary cultural and religious practices must be respected and both qualify for protection. ${ }^{39}$ Thus, denying a learner the right to manifest a genuinely held, but voluntary, cultural practice whilst at school was discrimination on the basis of culture. ${ }^{40}$

\section{WAS THE DISCRIMINATION UNFAIR AND IN CONTRAVENTION OF THE LAW?}

Having established that DGHS's code and decision was discriminatory, the central issue before the court was whether it was unfair as defined in section 14 of the Equality Act. Section 14 is a comprehensive section and has been criticized as being inelegantly drafted. Three separate enquiries have to be considered in order to determine whether the discrimination is unfair. Firstly, the section incorporates the court's jurisprudence on unfairness. In determining whether the discrimination is unfair regard must be had to the impairment of human dignity, the impact of the discrimination on the complainant, the position of the complainant in society and whether he or she suffers from past patterns of discrimination.

The second set of criteria are drawn from the limitation clause enquiry and regard has to be had to the nature and the extent of the discrimination, whether the discrimination is systemic in nature, whether the discrimination has a legitimate purpose, whether the discrimination achieves its purpose and whether there are less restrictive and less disadvantageous means of achieving the purpose.

The final set of criteria relate to whether the respondent has taken steps that are reasonable in the circumstances to accommodate diversity. As these criteria overlap considerably, it is difficult to apply this section.

Rather than engaging in the complicated exercise of reconciling the difference sets of overlapping criteria in order to create a coherent set of norms, the court accentuated the reasonable accommodation enquiry. It held that reasonable accommodation will always be an important factor in determining the fairness of discrimination but cautioned against reducing the test of unfairness to a test for reasonable accommodation. ${ }^{4}$

The court held that reasonable accommodation would be most appropriate where the discrimination arises from a rule or practice that is neutral on its face and is designed to serve a valuable purpose but which has a marginalizing affect on certain portions of society. ${ }^{42}$ In addition it would be particularly appropriate in localized contexts such as a workplace or school where a reasonable balance between conflicting interests may be struck more easily. ${ }^{43}$ Thus it would appear from the judgment that when a particular school is attempting to balance the broader concerns of discipline

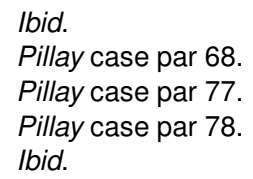


and the delivery of effective education against the manifestation of cultural or other rights of learners, the reasonable accommodation test would be most appropriate. Therefore the central question is whether the code and the decision made in terms of the code reasonably accommodate diversity. In order to apply this standard properly, schools must understand what is meant by "reasonable accommodation".

The school has to demonstrate that it has accommodated diversity. It cannot demand of the learner that he or she also demonstrate a reasonable accommodation of the school. Thus, once the genuineness of the belief is established, the school cannot demand that the learner desist or remove the cultural or religious symbol whilst at school. The notion that the school's interests and concerns are at one end of the spectrum with the learner's rights at the other end and that reasonable accommodation requires parties gravitating to a compromise position, was not accepted. Balancing the conflicting rights becomes an option if the school demonstrates that acceding to the learner's demands would create an undue burden. It is at this point that it becomes justifiable to search for a compromise position that does not impose an undue burden on the school and which does not limit the learner's rights unjustifiably.

Reasonable accommodation requires the school to take positive measures, even if this requires incurring expense or experiencing inconvenience, in order to allow all learners to enjoy their rights equally. This would mean that a school would be obliged to provide taps and other washing facilities in toilets to accommodate the religious and cultural practices of Muslim learners even if they are a minority and even if there are cost implications. In effect schools are required to reach out to accommodate all learners. The duty to accommodate reasonably may be both negative and positive. It may entail no more than providing an exemption and in other circumstances it may require that buildings be altered and expenditure incurred. The court stressed that "more than mere negligible effort is required to satisfy the duty to accommodate". ${ }^{44}$ The question is ultimately whether the school acted proportionately in the circumstances. ${ }^{45}$ The importance and genuineness of the belief will have to be considered together with the budgetary implications of acceding to the requests, if the school is required to take positive action to accommodate diversity. No court will expect a school to incur expenses disproportionately if it does not have the funds to do so. It may also not be possible to take all the positive steps required to fully accommodate diversity immediately. Most schools operate from a fixed budget and normal expenses have to be met. It may be permissible, depending on budgetary constraints for a school, to implement a plan of action to accommodate diversity fully progressively. However, this would not apply if the school is required to consider a request for a dispensation from its rules. This can be referred to as a negative duty to accommodate. In these circumstances an immediate decision must be made.

44 Pillay case par 76.

45 Pillay case par 86. 
The duty in the Pillay case was a negative one. In deciding whether there was reasonable accommodation, regard has to be had to the importance of the practice to the learner on the one hand and to the hardship that would be caused to the school by permitting the individual learner to engage in this practice. ${ }^{46}$

The court found that preventing Sunali from wearing the nose stud whilst she was at school would undermine the practice and constitute an infringement of her religious and cultural identity. ${ }^{47}$ Further it would have the symbolic effect of indicating that her religion and culture are not welcome at the school. ${ }^{48}$ The question according to the court was how important the belief or practice was to Sunali's religious or cultural identity. ${ }^{49}$ If she unequivocally states that the nose stud is central to her beliefs, then it was not for the court to inform her that she is wrong because others do not relate to her religion and culture in the same manner. ${ }^{50}$ In deciding the issue of subjective centrality, the school is permitted to have regard to a wide range of factors including evidence of the objective centrality of the practice to the community at large, the voluntariness of the practice and other relevant factors. ${ }^{51}$ There was little doubt of the genuineness and importance of the practice to Sunali and her mother.

However, the court emphasized that even the most vital practice of a religion or culture can be limited for the greater good. The issue is whether allowing Sunali to wear the nose stud would impose too great a burden on the school and its core activities. ${ }^{52}$ If the belief is particularly significant and closer to the core of an individual's identity, then a greater justification would be required from the school if it seeks to limit and not accede to the request. ${ }^{53}$ Not allowing the learner to manifest her religious and cultural rights is an infringement of her constitutional rights and thus has to be justified by the school. In deciding whether the school has justified its decision, regard must be had to a three-prong test:

- Is the school seeking to achieve a legitimate purpose $?^{54}$

- Does the limitation (the denial of the request) achieve that purpose $?^{55}$

- Are there less restrictive means available to achieve the purpose $?^{56}$

The school argued that allowing Sunali to wear the nose stud would adversely impact on the discipline in school and ultimately have a prejudicial

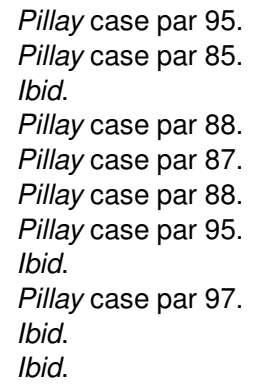


effect on the quality of education provided at the school. ${ }^{57}$ While its objective was laudable and clearly justifiable, the court held that there was no evidence that the granting of this dispensation, would affect the discipline of others negatively. ${ }^{58}$ Thus the school was held to have failed to demonstrate that the refusal of the request would enhance the objective of ensuring discipline at schools and of promoting the delivery of effective education. ${ }^{59}$

The court in the Pillay case subjected the justification proffered by DGHS to a more searching analysis than it required of Parliament in the Christian Education case. ${ }^{60}$ In the latter instance, Christian schools complained that the prohibition of corporal punishment in schools violated their freedom of religion and their freedom of association. Sachs $J$ recognized that the applicants genuinely perceived the law as an egregious violation of their right to practise and manifest their religious belief in accordance with the teachings and dictates of the Bible. The schools argued that the law was constitutionally offensive as no provision was made for exemptions to accommodate those whose freedom of religion was infringed by the law. There was thus a material similarity between the objection taken to the code in the Pillay case and the objection to the law prohibiting corporal punishment in the Christian Education case.

In Christian Education the court held:

"The outlawing of physical punishment in the school accordingly represented more than a pragmatic attempt to deal with disciplinary problems in a new way. It had a principled and symbolic function, manifestly intended to promote respect for the dignity and physical and emotional integrity of all children.",

There was no requirement on the legislature to demonstrate that the granting of exemption to Christian schools would subvert the broader objectives of prohibiting corporal punishment in public schools. The court made the assumption that this would occur. Had it required the legislature to provide such evidence, the legislature may well have failed to justify its decision. In the circumstance of the Christian Education case the court concluded that it was justifiable for the legislature to insist upon a blanket prohibition of corporal punishment.

It would have been extremely difficult for a school like DGHS to prove that the granting of the exemption would necessarily have an adverse effect on discipline and thus prejudice the delivery of effective education. Most governing bodies, parents and educators use their cumulative wisdom, experience and knowledge to adopt rules in a genuine and bona fide attempt to forestall undesirable events or consequences from occurring. It is the authors' submission that there ought to have been a greater acknowledgement and appreciation of the knowledge, experience and expertise of the Governing Body and of educators in the Pillay case as there

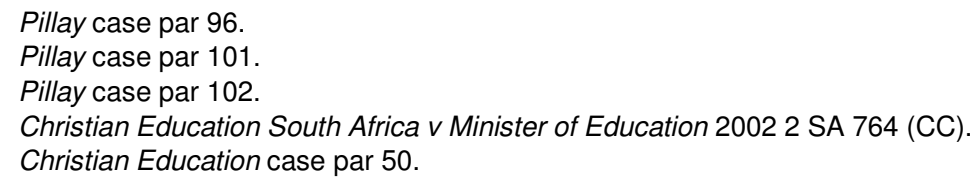


appears to have been of the wisdom of Parliament in the Christian Education case. Requiring evidence that the rule or norm would achieve its objectives now requires educators to rely on empirical data, previous events and probable consequences as opposed to depending on their instinctive reactions. Proper record-keeping of past events, upon which prospective rules are to be based, is now essential.

In this context, it is respectfully submitted that the reasonable accommodation test should have been interpreted as being whether the means adopted is reasonably likely to achieve the legitimate end of ensuring the delivery of effective education. Interpreting the requirement, designed to protect or advance in section 9(2) of the Constitution, the court in Minister of Finance $v$ Van Heerden, ${ }^{62}$ held:

"The future is hard to predict. However, they must be reasonably capable of attaining the desired outcome. If the remedial measures are arbitrary, capricious or display naked preference they could hardly be said to be designed to achieve the constitutionally authorized end. Moreover, if it is clear that they are not reasonably likely to achieve the end of advancing or benefiting the interests of those who have been disadvantaged by unfair discrimination, they would not constitute measures contemplated by s 9(2)."

Pitching the test at this less exacting level would have signaled a greater judicial appreciation of the expertise of the educators and an acknowledgment of the importance of the consultative and participatory process involving the school community. It would also allow an analysis of the broader steps taken by the institution to foster respect for the affected community of which the applicant is a member. While this suggestion may not have altered the outcome in the Pillay case, it would make the task of predicting the future, selecting the appropriate means and acting in accordance with such prediction less difficult for schools.

The other arguments of the school were dismissed quite easily. Neither the Constitution nor the Equality Act requires identical treatment in all instances. ${ }^{63}$ Thus other learners, not sharing the same genuineness of belief, cannot demand being treated the same as Sunali. The fact that the nose stud is also worn as a fashion symbol does not mean that it should not be respected when it is worn as a manifestation of a genuinely held cultural or religious belief. ${ }^{64}$ The court emphasized that the judgment only dealt with bona fide cultural and religious practices and did not deal with other forms of expression.$^{65}$ It recognized the importance of school uniforms in promoting a culture of discipline and respect for authority. ${ }^{66}$ It held that this was not a case about the constitutionality of school uniforms. ${ }^{67}$ Further it underscored the importance of rules in fostering a sense of discipline and preparing

62. Minister of Finance and Another v Van Heerden 2004 (6) SA 121

Pillay case par 103.

Pillay case par 106.

Pillay case par 107.

Pillay case par 100.

Pillay case par 101. 
learners for the demands of the real world. ${ }^{68}$ Accordingly the court concluded that allowing Sunali to use the nose stud would not have imposed an undue burden on the school and that a reasonable accommodation would have been achieved by allowing Sunali to wear the nose stud. ${ }^{69}$ The refusal to permit that amounted to unfair discrimination. ${ }^{70}$ The school was thus ordered to amend the code, provide for reasonable accommodation for deviations from the code on religious and cultural grounds and to provide a procedure for the application and granting of exemptions. ${ }^{7}$

A concern with the reasoning of the majority is that a "judicial discretion" is required of educators with inadequate guidance offered as to how this discretion is to be exercised. The question of whether acceding to the request would amount to an undue burden on the school translates to whether the school has reasonably accommodated diversity. This is resolved by reference to the three-prong test of whether the school is pursuing a legitimate purpose, whether the limitation achieves that purpose and whether there are less restrictive means available to achieve that purpose. Applying these criteria has even confused some judges. As Justice O'Regan noted in Dawood: ${ }^{72}$

"There is, however, a difference between requiring a court or tribunal in exercising a discretion to interpret legislation in a manner that is consistent with the Constitution and conferring a broad discretion upon an official, who is quite untrained in law and constitutional interpretations, and expecting that official, in the absence of direct guidance, to exercise the discretion in a manner consistent with the provisions of the Bill of Rights. Officials are often extremely busy and have to respond quickly and efficiently to many requests or applications. The nature of their work does not permit considered reflection on the scope of the constitutional rights or the circumstances in which a limitation of such rights is justifiable ... But it is important to interpret that obligation within the context of the role that administrative officials play in the framework of government, which is different from that played by judicial officials."

In accordance with the dicta in Dawood O'Regan $\mathrm{J}$ in Pillay expanded upon the thinking of the majority and provided useful and practical guidance to educators in determining whether exemptions should be granted. O'Regan J's comments are not inconsistent, but rather an important and necessary extension of the determination of the majority. The justice suggests that the code of conduct of the school was deficient in that it did not regulate the circumstances which would justify the granting of an exemption and the procedure which should be followed when applying for exemptions. $^{73}$ It was thus imperative for a school which establishes a code which may have the effect of discriminating against the learners on the grounds of culture and religion to establish a fair procedure for the determination of exemptions. She suggests a two-stage process. Firstly the

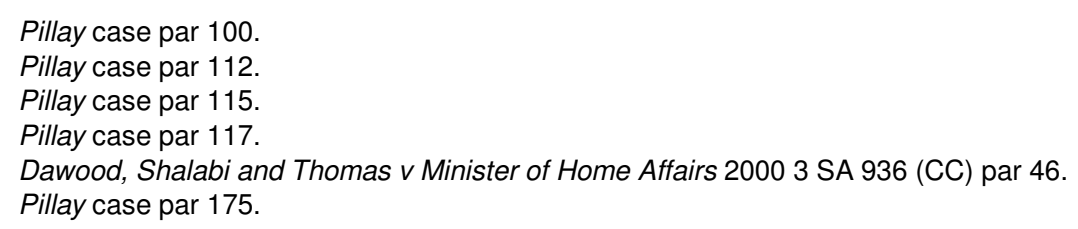


learner would have to provide either in writing or verbally, his or her reasons for seeking an exemption. The motivation must state the exact nature of the exemption sought, the reason for seeking the exemption and the importance to the learner of being granted the exemption.

It is the authors' recommendation that if the application is made verbally then the school should, if the learner is unable to do so, record the motivation in writing. Secondly, the school decision-making body would have to reflect on whether the exemption should be granted. ${ }^{74}$ Various factors would have to be considered in reaching a proportionate response. Based on the majority and part concurrence of O'Regan $\mathrm{J}$ the authors suggest the following for consideration by the various governing bodies that now have to draft appropriate rules.

\section{EXEMPTION PROCESSES}

Exemption from Uniform policies:

In order to:

a. celebrate cultural and religious diversity in the school context;

b. foster respect for the cultural and religious practices and diversity of all learners; and

c. maintain a disciplined and purposeful school environment, dedicated to the improvement and maintenance of the quality of the learning process

the following rule has, after consultation with the learners, parents and educators, been adopted:

1 All learners seeking exemption from compliance with the uniform policy of the school must submit representations to the Principal indicating the exemption requested, the reason for the exemption and the importance of the exemption being granted to the learner. All supporting documentation must be submitted.

2 All applications for exemptions must, subject to clause 3 below, be in writing.

3 If the learner and/or his or her parent/guardian is unable to submit the motivation in writing, the school will provide the necessary assistance to enable the learner to reduce his or her their oral representations to writing.

4 Upon receipt of such representations requiring exemption, the Principal of the school will refer the request to the Governing Body for consideration. The Governing Body may either consider the request itself or refer the matter to a subcommittee for consideration.

5 In deciding whether to grant the exemption, the Governing Body will consider the following factors:

$74 \quad$ Pillay case par 179. 
- the cultural or religious practice on which the application for an exemption is based and the importance of that practice to the learner concerned;

- whether the cultural or religious practice is mandatory or voluntary;

- whether the cultural or religious community considers it to be a practice which ordinarily warrants exemption from the school rules;

- the extent to which the ordinarily rules would be departed from in the event of the exemption being granted; and

- any evidence that the granting of the exemption would adversely affect discipline and the improvement and maintenance of the quality of the learning process at the school.

6 If the original motivation does not deal adequately with the considerations mentioned in 5 above, the Governing Body must invite the learner to deal specifically with these issues.

7 The Governing Body may consult relevant persons and bodies prior to rendering its decision. In making its decision, the decision-making body shall act in an informal and participatory manner.

8 The decision of the Governing Body will be in writing and will provide adequate reasons for its conclusions.

9 A learner who made the application and who is dissatisfied with the decision of the Governing Body may appeal to the Head of Department. Such appeals will be prosecuted in accordance with rules promulgated either by the Minister or by the member of the Executive Council having jurisdiction.

Having an internal appeal structure to deal with applications for exemptions will significantly ease the burden on the schools. The Pillay case was heard in three courts, with eleven judges considering the issue in the Constitutional Court. This must have been an exhausting and expensive process for all concerned. Educators must deliver on their primary responsibilities and not be pre-occupied with the vagaries of litigation. An internal administrative appeal tribunal set up by the provincial departments of education will provide inexpensive, expeditious and competent adjudication. If the appeals tribunal is staffed with persons able to exercise judicial discretion, then proper decisions can be made and the objectives of proportionality and respect for diversity can be achieved without an undue burden being placed either on the learner or the school.

\section{CONCLUSION}

It is singularly inapt and unhelpful to state, as does the South African Schools Act, that decisions made by educators must be consistent with the Constitution. This may serve as an aspirational statement but achieves no more. Educators, untrained in constitutional matters, will have little idea of the nature and scope of the duties imposed. In most instances educators will 
either act in a manner that they instinctively consider to be right or moral or alternatively rely on legal practitioners to make decisions. In the former instance there is a dependence on chance and in the latter, the wrong persons will be making the decision. The rationale of giving decision-making powers to governing bodies is to advance participatory democracy thus enabling communities themselves to make important decisions that affect their schooling. We need to reaffirm a commitment to this, and provide greater clarity on how the discretion is to be exercised. The granting of wide and unchecked discretion does not achieve this objective. The relevant constitutional and legal principles that have to be considered when exercising the discretion have to be identified and clearly articulated in an accessible fashion. The purpose of this article is to attempt to provide guidance to educators and governing bodies when deciding whether or not to grant exemptions from their uniform policies on the basis of religion and culture. The authors' draft rule is based on the judgment of the court in the Pillay case and stipulates both a process and the substantive criteria that must be considered when exercising this discretion. Schools must be provided with proper legislative guidance and administrative support to discharge their statutory obligations. It is simply unfair to require schools to exercise "judicial discretion" and get on with the job. 